\title{
COMPOSIÇÃO QUÍMICA DA MADEIRA DE EUCALIPTO COM DIFERENTES NÍVEIS DE DESBASTE
}

\author{
CHEMICAL COMPOSITION OF EUCALIPT WOOD WITH DIFFERENT LEVELS OF THINNING
}

Antônio José Vinha Zanuncio ${ }^{1}$ Jorge Luiz Colodette ${ }^{2}$ Fernando Jose Borges Gomes ${ }^{3}$ Angélica de Cassia Oliveira Carneiro ${ }^{2}$ Benedito Rocha Vital ${ }^{2}$

\begin{abstract}
RESUMO
O objetivo deste estudo foi avaliar diferentes regimes de desbaste em plantios silviculturais de clones de eucalipto (Eucalyptus urophylla x Eucalyptus grandis) para produção de madeira visando à obtenção de celulose e carvão com a finalidade de verificar se este efeito poderia afetar quantitativamente a proporção dos componentes químicos da madeira. O espaçamento inicial médio entre plantas foi de $3 \times 3 \mathrm{~m}$ e os tratamentos foram: $\mathrm{T} 1=$ testemunha, $\mathrm{T} 2$, T 3 e T 4 com desbaste de $20 \%, 35 \%$ e $50 \%$ da área basal presente, respectivamente. Os resultados foram submetidos ao teste de Tukey com 5\% de probabilidade. De acordo com os resultados, constatou-se que o teor de lignina resultante do tratamento T4 foi maior que o dos demais; o de grupos urônicos do T1 foi semelhante ao dos demais tratamentos, mas os teores dos $\mathrm{T} 2$ e T4 diferiram entre si. O teor de extrativos do T1 foi semelhante ao dos T2 e T3 e menor que o do T4; o de carboidratos do T1 foi semelhante ao do T3 e superior aos demais. Concluiu-se que o desbaste aumenta a qualidade da madeira para ser utilizada como fins energéticos, como produção de carvão, mas não aumenta a produtividade de madeira destinada à confecção de celulose e papel.
\end{abstract}

Palavras-chave: Eucalyptus; desbaste; lignina.

\begin{abstract}
The objective of this study was to evaluate different thinning regimes in forest plantations of eucalypt (Eucalyptus grandis $\mathrm{x}$ Eucalyptus urophylla) clones to produce timber for cellulose and charcoal to verify whether this effect could affect the proportion of the chemical components of wood. The average initial spacing between plants was $3 \times 3 \mathrm{~m}$ and the treatments were: $\mathrm{T} 1=$ control, $\mathrm{T} 2$, T3and $\mathrm{T} 4$ with thinning $20 \%$, $35 \%$ and $50 \%$ of the basal area, respectively. The results were analyzed by Tukey test at $5 \%$ probability. According to the results found the lignin content from treatment T4 was higher than that of the others; the groups of uronic acids of the T1 was similar to all other treatments, but the levels of T2 and T4 differed between them. The extractives content of T1was similar to the T2 and T3 and lower than that of theT4; the carbohydrates of $\mathrm{T} 1$ were similar to that of $\mathrm{T} 3$ and higher than the others. It was concluded that thinning increases the quality of the wood to be used as energy purposes, such as charcoal production, but it did not increase productivity for wood pulp and paper production.
\end{abstract}

Keywords: Eucalyptus; grinding;lignin.

1 Engenheiro Florestal, Mestrando em Ciência e Tecnologia da Madeira, Universidade Federal de Lavras, Campus Universitária, Caixa Postal 3037, CEP 37200-000, Lavras (MG), Brasil. ajvzanuncio@yahoo.com.br

2 Engenheiro Florestal, Dr., Professor do Departamento de Engenharia Florestal, Centro de Ciências Agrárias, Universidade Federal de Viçosa, Av. Peter Henry Rolfs, s/n, CEP36570-000, Viçosa (MG), Brasil. colodette@ufv.br/ cassiacarneiro@ufv.br, bvital@ufv.br

3 Engenheiro Florestal, Msc., Doutorando em Ciência Florestal, Universidade Federal de Viçosa, Av. Peter Henry Rolfs, s/n, CEP 36570-000, Viçosa (MG), Brasil. fjbgomes@yahoo.com.br

Recebido para publicação em 01/12/2009 e aceito em 23/08/2012 


\section{INTRODUÇÃO}

A madeira proveniente de eucalipto representa a principal fonte de fibras nos países da América do Sul para a produção de celulose e papel. O Brasil ocupa lugar de destaque na fabricação mundial de celulose de fibra de eucalipto, sendo que atingiu $31 \%$ da capacidade global desse produto em 2008 (MAGATON et al., 2008).

A produção de carvão vegetal depende da demanda do setor siderúrgico. O Brasil é o maior produtor mundial de aço utilizando o carvão vegetal para fins de redução do minério de ferro. Esse setor está em expansão e gera milhares de postos de trabalho e impostos (BRITO e CINTRA et al., 2004).

Para sustentar o crescimento destes setores, é fundamental que os estudos sobre a qualidade da madeira sejam aprofundados. A composição química do material lenhoso exerce grande influência no processo de beneficiamento da madeira e o teor de cada constituinte sofre grande influência do ambiente.

Extrativos são compostos da madeira não pertencentes à parede celular, com baixa ou média massa molecular, encontrados em pequenas quantidades e podem ser extraídos em água e solventes orgânicos neutros e presentes em toda árvore, mas principalmente, na casca (BARRICHELO e BRITO, 1985). Incluem óleos essenciais, resinas, taninos, graxas e pigmentos (GARDNER e HILLIS, 1962). Alguns extrativos como ácidos resinosos e polifenois reagem com o hidróxido de sódio do licor negro durante o processo de polpação, reduzindo a carga álcali e dificultando o processo de fabricação de pasta celulósica. No entanto, alguns extrativos podem aumentar o poder calorífico da madeira para produção de energia.

As ligninas são compostos de natureza aromática e tridimensional, baseados, estruturalmente, em três tipos de álcoois que possuem unidades de fenil-propano ligadas a grupos metoxílicos e hidroxílicos, dependendo do tipo de madeira e com elevado peso molecular (TRUGILHO et al., 1996). As unidades de fenil-propano são unidas por ligação éter (C-OC), que são mais fracas, ou carbono-carbono (C-C), mais fortes. O primeiro grupo é dominante, pois representa $2 / 3$ ou mais das ligações das ligninas (SJOSTROM, 1993). A maioria das ligninas se encontra na parede secundária da planta, todavia, na lamela média, são proporcionalmente mais abundantes. Aumentam a rigidez da parede ce- lular, atuam como agente cimentante entre as células, reduzem a permeabilidade da parede, protegem a madeira contra micro-organismos, aumentam a resistência da planta à compressão e permite o crescimento longitudinal (WILLFÖR et al., 2006 e WARDROP, 1971). As ligninas são geralmente formadas pelas unidades siringila e guaiacila (lignina $\mathrm{S}-\mathrm{G})$ nas folhosas e pelas unidades guaiacila e $p$ -hidroxifenila (lignina G-H) em coníferas e os três tipos de unidades monoméricas (lignina $\mathrm{H}-\mathrm{G}-\mathrm{S}$ ) em gramíneas (BARBOSA et al., 2008).

A celulose e hemiceluloses na madeira representam o total de polissacarídeos denominados, também, como holocelulose. A celulose é um polissacarídeo de cadeia linear com a estrutura de um polímero de comprimento tão grande que a torna insolúvel em solventes orgânicos, água, ácidos e bases diluídas à temperatura ambiente (FENGEL e WEGENER, 1984). A celulose é constituída de unidades de $\beta$-D-anidroglucopiranose unidas por ligações do tipo (1-4) e sua estrutura possui partes amorfas, carbonos 2, 4, 6 e cristalinas, carbonos 1 , 3, 5 (MORAIS et al., 2005). As hemiceluloses são polissacarídeos de baixo peso molecular, frequentemente, associados à celulose nos tecidos das plantas. Nas plantas vasculares terrestres são extremamente ramificadas e constituídas de uma gama de unidades de açúcares, como D-xilose, D-manose, D-galactose, D-glicose, L-arabnose, ácido 4-0-metilglicurônico, ácido D- galactourônico e ácido D-glicurônico (SJÖSTRÖM, 1993).

Os ácidos urônicos estão presentes em algumas hemiceluloses, especialmente nas xilanas, como ácido 4-0-metilglicourônico (MeGlcA's) e modificam-se em sua estrutura, transformando-se em ácidos hexenourônicos durante o processo de polpação.

O objetivo deste trabalho foi avaliar como o desbaste influencia a composição química da madeira de clones de eucalipto (Eucalyptus urophylla $\mathrm{x}$ Eucalyptus grandis) com vistas à produção de madeira para fabricação de carvão e polpa celulósica.

\section{MATERIAL E MÉTODOS}

$\mathrm{O}$ experimento foi realizado em um talhão de eucalipto (Eucalyptus urophylla x Eucalyptus grandis) em Martinho Campos - Minas Gerais. Cada talhão foi dividido em quatro faixas com tamanhos semelhantes, representando os quatro tratamentos. Espaçamento inicial médio entre plantas foi de $3 \times 3 \mathrm{~m}$ e os tratamentos foram: T1= testemu- 
nha, $\mathrm{T} 2=20 \%$ de desbaste em área basal presente, $\mathrm{T} 3=35 \%$ de desbaste em área basal presente, $\mathrm{T} 4=$ $50 \%$ de desbaste em área basal presente, em todos os casos eliminando os indivíduos com menor crescimento. O desbaste foi realizado em julho de 2003, quando as árvores tinham 55 meses. As árvores foram colhidas quando tinham 117 meses de idade e 62 meses pós-desbaste (em setembro de 2008).

As amostras foram transformadas em serragem em moinho tipo Wiley (Norma TAPPI $\mathrm{T}$ 257 om-92 1992). O material empregado nas análises químicas passou por peneira de malha de 40 mesh e ficou retido na de 60 mesh (ASTM) e seco em sala climatizada a $23 \pm 1^{\circ} \mathrm{C}$ de temperatura e $50 \pm 2 \%$ de umidade relativa.

As análises químicas e as normas adotadas foram: o teor de extrativos totais pela norma Tappi T 264 cm-97; o de lignina insolúvel pelo método Klason modificado (GOMIDE e DEMUNER, 1986); o de lignina solúvel em ácido, a partir do filtrado resultante da análise da lignina Klason pela leitura em espectrofotômetro (GOLDSCHIMID, 1971) e o de lignina total pela soma da lignina residual com a solúvel em ácido. Os teores de ácidos urônicos (SUNDBERG, 1996) e carboidratos (açúcares) (WALLIS et al., 1996) foram, também, determinados.

\section{RESULTADO E DISCUSSÃO}

O teor de lignina insolúvel em ácido variou de 27,5 a $30,2 \%$ e o da solúvel de 2,8 a $3,1 \%$ entre tratamentos (Tabela 1), semelhante aos valores para a lignina solúvel e insolúvel de madeiras de Eucalyptus grandis, Eucaliptus nitrens e Eucalyptus urophylla encontrados na literatura (QUEIROZ et al. 2004; MOKFIENSKI et al. 2008 e GOMIDE et al. 2005).

A lignina insolúvel do T4 foi superior à dos demais, indicando que o desbaste de $50 \%$ da área basal pode aumentar o teor de lignina insolúvel em clones de eucalipto. O teor de lignina solúvel, ou seja, aquela que não condensa durante a hidrólise ácida pelo método de Klason, foi semelhante entre tratamentos e o da lignina total seguiu tendência semelhante da insolúvel

Madeiras com maior teor de lignina resultam em carvão com maior poder calorífico, mas um alto teor desse material no processo de produção da polpa celulósica aumenta o gasto de reagentes (GOMIDE et al., 2006). Isto mostra que o T4 deve ser evitado para o setor de celulose e papel, porém, esta intensidade de desbaste pode ser interessante para a produção de carvão vegetal.

O teor de ácidos urônicos variou de 3,94 a 4,79\% (Tabela 2). Amostras de clones de diversas

TABELA 1: Teores de lignina insolúvel, solúvel e total (\%) da madeira de eucalipto sem desbaste (T1testemunha) e com $25 \%$ (T2), $35 \%$ (T3) ou $50 \%$ (T4) de desbaste.

TABLE 1: Levels of insoluble, soluble and total (\%) lignin of eucalyptus wood without thinning (T1control) and $25 \%$ (T2), 35\% (T3) or 50\% (T4) thinning.

\begin{tabular}{cccc}
\hline Tratamentos & Lignina Insolúvel (\%) & Intervalo (\%) & Desvio Padrão \\
\hline T1 27,5 a & 26,8 a 29,2 & 0,577 \\
T2 & 28,4 a & 27,5 a 29,3 & 0,717 \\
T3 & 28,3 a & 27,1 a 30.0 & 0,851 \\
T4 & 30,2 b & 29,7 a 31.00 & 0,492 \\
\hline & Lignina Solúvel (\%) & Intervalo (\%) & Desvio Padrão \\
\hline T1 & 3,1 a & 2,9 a 3,3 & 0,210 \\
T2 & 2,8 a & 2,7 a 3,2 & 0,169 \\
T3 & 2,9 a & 2,7 a 3,0 & 0,104 \\
T4 & 2,9 a & 2,5 a 3,3 & 0,319 \\
\hline & Lignina Total (\%) & Intervalo (\%) & Desvio Padrão \\
\hline T1 & 30,7 a & 30,1 a 31,2 & 0,445 \\
T2 & 31,2 a & 30,3 a 32,0 & 0,588 \\
T3 & 31,2 a & 30,1 a 31,9 & 0,797 \\
T4 & $33,1 \mathrm{~b}$ & 33,0 a 33,6 & 0,215 \\
\hline
\end{tabular}

Médias seguidas de, pelo menos, uma mesma letra por coluna não diferem pelo teste de Tukey $(\mathrm{P}>0,05)$. 
espécies de eucalipto mostraram teores de ácidos urônicos de 3,2 a 4,7\% (GOMIDE et al., 2005), semelhantes ao deste estudo, porém, maior que a variação entre $1,5 \%$ e $3,1 \%$ para folhosas da região amazônica (SANTANA e OKINO, 2007).

$\mathrm{O}$ teor de ácidos urônicos do T1 foi semelhante aos demais, contudo, os tratamentos T2 e T4 diferiram entre si, o que mostra que o desbaste não afetou esse material. Os ácidos urônicos são contabilizados no teste de medição da lignina solúvel em polpa celulósica, o que afeta a precisão do teste (ZANUNCIO e COLODETTE, 2011).

A estrutura dos ácidos urônicos é convertida em ácido hexenurônico através da via $\beta$ - eliminação durante o processo de polpação. Este último não reage em meio alcalino, o que afeta negativamente o desempenho da pré-O2 (DAHLMAN et. al., 1996), contudo, protegem as xilanas contra reações de despolimerização terminal (JIANG et al., 2000).

Os teores dos extrativos variaram de 2,1 a $2,5 \%$ (Tabela 3), valores próximos aos relatadas para várias espécies de eucalipto (GOMIDE et al., 2005). O tratamento $\mathrm{T} 1$ foi semelhante aos $\mathrm{T} 2$ e T3, enquanto o T4 mostrou maior teor de extrativos. Na indústria de celulose e papel, esses extrativos podem formar depósitos denominados "pitch" no maquinário das fábricas e reduzir a produção, aumentar o custo de manutenção e defeitos no produto final (CRUZ et al., 2006). Isso é especialmente verdadeiro para a classe de extrativos apolares, tipicamente os ácidos graxos, álcoois graxos e ésteres de ácidos graxos com hormônios vegetais tais como sistosterol e outros ésteres.

TABELA 2: Teor de ácidos urônicos (\%) da madeira de eucalipto sem desbaste (T1) testemunha ou com $25 \%$ (T2), $35 \%$ (T3) ou $50 \%$ (T4) de desbaste.

TABLE 2: Levels of uronic acids (\%) of eucalyptus wood without thinning (T1- control) or with $25 \%$ (T2), $35 \%$ (T3) or $50 \%$ (T4) thinning.

\begin{tabular}{cccc}
\hline Tratamentos & $\begin{array}{c}\text { Ácidos } \\
\text { Urônicos (\%) }\end{array}$ & $\begin{array}{c}\text { Intervalo } \\
(\%)\end{array}$ & $\begin{array}{c}\text { Desvio } \\
\text { Padrão }\end{array}$ \\
\hline T1 & $4,4 \mathrm{ab}$ & 3,8 a 5,00 & 0,44 \\
T2 & $4,8 \mathrm{a}$ & 4,2 a 5,4 & 0,41 \\
T3 & $4,3 \mathrm{ab}$ & 3,7 a 5,1 & 0,57 \\
T4 & $3,9 \mathrm{~b}$ & 3,7 a 4,4 & 0,28 \\
\hline
\end{tabular}

Médias seguidas de, pelo menos, uma mesma letra por coluna não diferem pelo teste de Tukey $(\mathrm{P}>0,05)$.
TABELA 3: Teor de extrativos (\%) da madeira de eucalipto sem desbaste (T1testemunha) ou com $25 \%$ (T2), $35 \%$ (T3) ou $50 \%$ (T4) de desbaste.

TABLE 3: Levels of extractives (\%) of eucalyptus wood without thinning (T1- control) or with $25 \%$ (T2), $35 \%$ (T3) or $50 \%$ (T4) thinning.

\begin{tabular}{cccc}
\hline Tratamentos & $\begin{array}{c}\text { Teor de } \\
\text { Extrativo (\%) }\end{array}$ & $\begin{array}{c}\text { Intervalo } \\
(\%)\end{array}$ & Desvio Padrão \\
\hline T1 & $2,1 \mathrm{a}$ & $1,9 \mathrm{a} 2,3$ & 0,17 \\
$\mathrm{~T} 2$ & $2,2 \mathrm{a}$ & $2,1 \mathrm{a} 2,2$ & 0,10 \\
$\mathrm{~T} 3$ & $2,2 \mathrm{a}$ & $2 \mathrm{a} 2,3$ & 0,12 \\
$\mathrm{~T} 4$ & $2,5 \mathrm{~b}$ & $2,4 \mathrm{a} 2,7$ & 0,11 \\
\hline
\end{tabular}

Médias seguidas de, pelo menos, uma mesma letra por coluna não diferem pelo teste de Tukey $(\mathrm{P}>0,05)$

A presença de altos teores de substâncias como extrativos e lignina favorece a produção de carvão com maior densidade e mais resistente em termos de propriedades físico-mecânicas. Por isto, para madeiras de eucalipto (Eucalyptus urophylla $\mathrm{x}$ Eucalyptus grandis), o tratamento T4 pode ser recomendado para madeiras destinadas para a produção de carvão vegetal. Os demais tratamentos são recomendados para a madeira destinada para produção de celulose e papel.

$\mathrm{O}$ teor de carboidratos variou entre 36,7 e $42,3 \%$ para glicanas e de 12,0 a $14,0 \%$ para o de xilana, enquanto mananas, galactanas e arabinanas tiveram proporções pouco significativas (Tabela 4). Esses valores foram semelhantes aos relatados para madeiras de eucalipto e de folhosas da região amazônica (MOKFIENSKI et al., 2008; FERREIRA et al., 2006; SANTANA e OKINO, 2007).

Os tratamentos T1 e T3 apresentaram maiores teores de glicanas e polissacarídeos totais. Para o teor de xilanas, o tratamento T1 foi superior aos demais. Isto contrasta com Pinus elliottii, quando o desbaste não influenciou o teor de celulose (PEREIRA e TOMASELLI, 2004). Para Eucalyptus dunnii, menor espaçamento do povoamento resulta em madeira com maior teor de xilanas (FERREIRA et al., 2006), resultado compatível com este estudo, pois, em ambos, os maiores teores foram constatados em povoamentos com maior competição. Os polissacarídeos da madeira são importantes para a fabricação de celulose e papel e no presente trabalho, o desbaste não aumentou o teor dos mesmos. Esta recomendação também se aplica para plantios de Pinus taeda, pois, a madeira de plantas sem desbaste 
TABELA 4: Carboidratos (\%) de madeira de eucalipto sem desbaste (T1- testemunha) ou com 25\% (T2), $35 \%$ (T3) ou $50 \%$ (T4) de desbaste.

TABLE 4: Carbohydrates (\%) of eucalyptus wood without thinning (T1- control) or with $25 \%$ (T2), $35 \%$ (T3) or $50 \%$ (T4) thinning.

\begin{tabular}{ccccccc}
\hline \multirow{2}{*}{ Tratamentos } & \multicolumn{7}{c}{ Carboidratos (\%) } \\
\cline { 2 - 7 } & Glicanas & Xilanas & Mananas & Galactanas & Arabinanas & Total \\
\hline T1 & $42,3 \mathrm{a}$ & $14,0 \mathrm{a}$ & 0,72 & 0,77 & 0,18 & $57,99 \mathrm{a}$ \\
T2 & $38,00 \mathrm{bc}$ & $12,3 \mathrm{c}$ & 0,75 & 0,61 & 0,18 & $51,83 \mathrm{bc}$ \\
T3 & $40,00 \mathrm{ab}$ & $13,1 \mathrm{~b}$ & 0,74 & 0,64 & 0,18 & $54,63 \mathrm{ab}$ \\
T4 & $36,7 \mathrm{c}$ & $12,0 \mathrm{c}$ & 0,70 & 0,70 & 0,17 & $50,30 \mathrm{c}$ \\
\hline
\end{tabular}

Médias seguidas de, pelo menos, uma mesma letra por coluna não diferem pelo teste de Tukey $(\mathrm{P}>0,05)$.

é melhor para a produção de polpa celulósica que aquelas com desbastes (SANQUETTA et al., 2004).

\section{CONCLUSÃO}

O tratamento silvicultural com desbaste favoreceu a biossíntese de compostos como ligninas e extrativos, mas tendeu a diminuir o teor de polissacarídeos durante o ciclo produtivo. Isto indica que o desbaste aumenta a qualidade da madeira para fins energéticos, como produção de carvão, mas não melhora a destinada à produção de celulose e papel.

\section{AGRADECIMENTOS}

Ao Conselho Nacional de Desenvolvimento Científico e Tecnológico (CNPq) e a Fundação de Amparo à Pesquisa do Estado de Minas Gerais (FAPEMIG).

\section{REFERÊNCIAS BIBLIOGRÁFICAS}

BARBOSA, L. C. A. et al. Determinação da relação siringila/guaiacila da lignina em madeiras de eucalipto por pirólise acoplada à cromatografia gasosa e espectrometria de massas (PI - CG/EM). Química Nova, São Paulo, v. 31, n. 8, p. 20352041, dez. 2008.

BARRICHELO, L. E. G.; BRITO, J. O. Química da Madeira. Piracicaba: ESALQ, 1985. 125 p.

BRITO, J. O.; CINTRA, T. C. Madeira para energia no Brasil: realidade, visão estratégica e demandas de ações. Biomassa \& Energia, Viçosa, v. 1, n. 2, p. 157-163, jul./dez. 2004.

CRUZ, M. P. et al. Caracterização química do "pitch" em indústria de celulose e papel de Eucalyptus. Química Nova, São Paulo, v. 29, n. 3, p. 459-466, maio/jun. 2006.
DAHLMAN, O.; MORCK, R.; LARSSON, P. T. Effects of TCF-bleaching on hemicelluloses. In: INTERNATIONAL PULP BLEACHING CONFERENCE, 1996, Washington. Proceedings... Washinton: Tappi, 1996. p. 371-376.

FENGEL, D.; WEGENER, G. Wood, Chemistry, Ultraestructure, Reactions. New York: Waster \& Grugter, 1984, $613 \mathrm{p}$.

FERREIRA, C. R. et al. Avaliação tecnológica de clones de eucalipto: parte 1 - qualidade da madeira para produção de celulose Kraft. Scientia Forestalis, Piracicaba, n. 70, n. 1, p. 161-170, abr. 2006.

GARDNER, J. A. F.; HILLIS, W. E. The Influence of Extractives on the Pulping of Wood. In: Wood Extractives. HILLIS, W. E. Ed. New York: Academic Press, 1962.

GOLDSCHIMID, O. Ultraviolet spectra. In: SARKANEN, K. V.; LUDWING, C. H. (Eds) Lignins. New York: Wiley Interscience, 1971. p. 241-266.

GOMIDE, J. L. Tecnologia e Química da Produção de Celulose. Viçosa: Laboratório de Celulose e Papel, Universidade Federal de Viçosa, 2006. 235 p. GOMIDE, J. L.; DEMUNER, B. J. Determinação do teor de lignina em material lenhoso: método Klason modificado. O Papel, São Paulo, v. 47, n. 8, p. 36-38, ago. 1986.

GOMIDE, J. L. et al. Caracterização tecnológica, para produção de celulose, da nova geração de clones de Eucalyptus do Brasil. Revista Árvore, Viçosa, v. 29, n. 1, p. 129-137, jan./fev. 2005.

JIANG, Z.; VAN LIEROP, B. V.; BERRY, R. Hexenuronic acid groups in pulping and bleaching chemistry. Tappi Journal, Atlanta, v. 83, n. 1, p. 167-175, 2000.

MAGATON, A. S.; PILÓ-VELOSO D.; 
COLODETTE, J. L. Caracterização das $O$-acetil(4-O-metilglicurono) xilanas isoladas da madeira de Eucalyptus urograndis. Química Nova, São Paulo, v. 31, n. 5, p. 1085-1088, set. 2008.

MOKFIENSKI, A. et al. A importância relativa da densidade de madeira e do teor de carboidratos no rendimento de polpa e na qualidade do produto. Ciência Florestal, Santa Maria, v. 18, n. 3, p. 407419, jul./set. 2008.

MORAIS, S. A. L.; NASCIMENTO, E. A.; MELO, D. C. Análise da madeira de Pinus oocarpa, parte I - Estudos dos constituintes moleculares e extrativos voláteis. Revista Árvore, Viçosa, v. 29, n. 3, p. 461470, maio/jun. 2005.

PEREIRA, J. C. D.; TOMASELLI, I. A influência do desbaste na qualidade da madeira de Pinus elliottii Engelm. var. elliottii. Boletim de Pesquisa Florestal, Colombo, n. 49, n. 1, p. 61-81, jul./dez. 2004.

QUEIROZ, S. C. S. et al. Influência da densidade básica da madeira na qualidade da polpa kraft de clones hibrídos de Eucalyptus grandis w. Hill ex Maiden x Eucalyptus urophylla S.T. Blake. Revista Árvore, Viçosa, v. 28, n. 6, p. 901-909, nov./dez. 2004.

SANQUETTA, C. R. et al. Produção de madeira para celulose em povoamentos de Pinus taeda submetidos a diferentes densidades de plantio e regimes de desbaste: abordagem experimental. Cerne, Lavras, v. 10, n. 2, p. 154-166, jul./dez. 2004.

SANTANA, M. A. E.; OKINO, E. Y. A. Chemical composition of 36 Brazilian Amazon forest wood species. Holzforschung, Alemanha. v. 61, n. 5, p.
469-477, Aug. 2007.

SJÖSTRÖM, E. Wood chemistry: fundamentals and applications. $2^{\text {nd }}$ ed. New York: Academic Press, 1993. $293 \mathrm{p}$.

SUNDBERG, A. et al. Determination of hemicelluloses and pectins in wood and pulp fibers by acid methanolysis and gas chromatography. Nordic Pulp \& Paper Research Journal, Stockholm, n. 4, p. 216-220, Feb. 1996.

TAPPI - TECHNICAL ASSOCIATION OF THE PULP AND PAPER INDUSTRY. Tappi Standard Methods, Atlanta: TAPPI, 2000-2002.

TRUGILHO, P. F.; LIMA, J. T.; MENDES, L. M. Influência da idade nas características físicoquímicas e anatômicas da madeira de Eucalyptus saligna. Cerne, Lavras, v. 2, n. 1, p. 83-93, jul./dez. 1996.

WALLIS, A. F. A.; WEARNE, R. H.; WRIGHT, P. J. Chemical analysis of polysaccharides in plantation eucalypt woods and pulps. Appita, Australia, v. 49, n. 4, p. 258-262, jul. 1996.

WARDROP, A. B. Occurrence and Formation in Plants. In: SARKANEN, K.V.; LUDWIG, C. H. Lignins, occurrence, formation, structure and reactions. New York: John Wiley, 1971, p. 19-32. WILFÖR, S. M.; SMEDS, A. I.; HOLMBOM, B. R. Chromatographic analysis of lignans. Journal of Chromatography A, Estados Unidos, v. 1112, n. 1-2, p. 64-77, abr. 2006.

ZANUNCIO, A. J. V.; COLODETTE, J.L. Teores de lignina e ácidos urônicos na madeira e polpa celulósica de eucalipto. Revista Árvore, Viçosa, v. 35, n. 2, mar./abr. 2011. 